\title{
Corrosion studies of mild steel in sulphuric acid medium by acidimetric method
}

\author{
S.O. Adejo, ${ }^{1,2^{*}}$ S.G. Yiase, ${ }^{1}$ L. Leke, ${ }^{1}$ M. Onuche,${ }^{1}$ M.V. Atondo ${ }^{1}$ \\ and T.T. Uzah ${ }^{1}$ \\ ${ }^{I}$ Department of Chemistry, Benue State University, Makurdi, Nigeria \\ ${ }^{2}$ Centre for Food Technology and Research, Benue State University Makurdi, Nigeria \\ *sadejo@bsum.edu.ng, soadejo@gmail.com
}

\begin{abstract}
Many corrosion monitoring techniques are available to study the behaviour of inhibitors in various media. Common among these techniques are weight loss, gasometric, thermometric, acidimetric, electrochemical impedance spectroscopy and a host of others. Each of these techniques has its strengths and weaknesses. While some of them are quite prone to errors, others require, extremely, expensive instrumentation. The acidimetric technique is, however, the least applied of among these techniques, in spite of its obvious advantages of simplicity, less prone to error and inexpensiveness. In this research work, we applied the acidimetric technique to the study of corrosion inhibition of mild steel in $\mathrm{H}_{2} \mathrm{SO}_{4}$ medium using urea, an organic molecule, as an inhibitor. The efficacy of the technique was then compared with an established and commonly applied corrosion monitoring technique; the weight loss technique. The two techniques were found out to give quite comparable results. However, the acidimetric technique was found to be faster, simpler, and yielded comparatively better results. The inhibition efficiency, \%IE, which has the same trend for the two methods, decreased with increase in temperature, suggestive of physisorption. This was collaborated by values of activation energy, $E_{\mathrm{a}}$, which are all below $80 \mathrm{~kJ} / \mathrm{mol}$. The adsorption mechanism of urea adsorption onto the metal surface was, therefore, resolved with the use of Adejo-Ekwenchi isotherm adsorption model to be physisorption, with the best fit adsorption isotherms being the Langmuir and El-Awady isotherm models.
\end{abstract}

Key words: corrosion, acidimetric technique, weight loss technique, efficacy, adsorption isotherm.

Received: May 8, 2018. Published: January 21, 2019

doi: $\underline{10.17675 / 2305-6894-2019-8-1-5}$

\section{Introduction}

Corrosion, a deterioration process of a material due to reaction with its surroundings, is a natural phenomenon, predominantly, encountered in metal and their alloy products [1-3]. 
The enormity of the cost of corrosion to the economy of any nation cannot be overemphasized. In addition to the huge cost, corrosion is also to be blamed for many of the disasters that cause the loss of life and devastating pollution of the environment [1]. In spite of much advancement in the field of corrosion science and engineering, the phenomenon of corrosion remains a major challenge nations have to grapple with. Many corrosion assessment techniques are available. Examples of such techniques are weight loss, gasometry, thermometry and electrochemical impedance spectroscopy, cyclic potentiodynamic polarisation, galvanic current, electrochemical noise, conductivity, biological counts, hydrogen penetration and a host of others. However, each technique has its strengths and weaknesses [2]. For example, the weight loss method, which is usually the first choice method for evaluation of inhibition efficiency, involves procedures for massloss coupon cleaning and analysis that are laborious and not too good for short exposure periods. The other methods may require quite expensive instruments. Acidimetric method is a method which rarely finds application in corrosion studies, in spite of its advantages. The very important attributes of acidimetric method are simplicity of measurement and rapidity of probe response. However, it has some weaknesses; inaccuracy of results in strong solution, interferences from ions and frequency of required maintenance [4]. But for most practical situations these weaknesses are rarely applicable.

Urea is an organic compound containing clear features for corrosion inhibition $[5,6]$, as it contains nitrogen and oxygen atoms and has the formula the structure $\mathrm{CO}\left(\mathrm{NH}_{2}\right)_{2}$. The structure of urea is shown in Figure 1 below

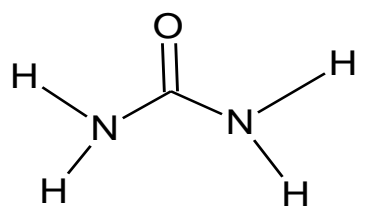

Figure 1. Structure of urea.

The presence of oxygen and nitrogen atoms gives the compounds their potential corrosive properties. The availability of lone pair electrons on these atoms can facilitate either electron sharing or transfer from the inhibitor to the metal [6]. It has been generally proven that heteroatom organic substances containing mainly oxygen, sulphur, nitrogen atoms, and multiple bonds in the molecules can be adsorbed onto the metal surface, as the active centres for the process of adsorption onto the metal surface. And it has been shown that the efficiency, generally, follows the sequence $\mathrm{O}<\mathrm{N}<\mathrm{S}<\mathrm{P}$ [7-9].

The basis of the acidimetric method is the response of $\mathrm{pH}$ to corrosion reaction of a material in acidic solution. $\mathrm{pH}$ has be adjudged as a single most important factor to measure the corrosiveness of aqueous process [4]. In this research work we, therefore, applied the acidimetric method to monitor the corrosion of mild steel in $0.5 \mathrm{M} \mathrm{H}_{2} \mathrm{SO}_{4}$ using urea as inhibitor. In order to ascertain the reliability of the method the results generated 
were, thus, compared with those of weight loss technique using same inhibitors. The weight loss technique has, indeed, been acclaimed as the best and simplest of all corrosion monitoring techniques $[10,11]$.

\section{Materials and Methods}

\section{Materials}

The following materials were used for the study: mild steel of composition (\%W) [Mn (0.56), P (0.04), C (0.27), Si (0.25), S (0.04) and the rest iron], sand paper, pH meter (H19024 Hanna Instruments), sulphuric acid (May and Baker Ltd, England), ethanol $(\mathrm{BDH})$, acetone $(\mathrm{BDH})$, desiccator, electric weighing balance (Model: ae Adam AFP: $d \pm$ $0.0001 \mathrm{~g}$ ), thermostated water-bath (Clifton Nickel-Electro Ltd, England), thermometer, beakers, thread, emery paper and retort stands. Analytical grade urea was purchased from Tianjin Kermel Chemical Reagent Co. Ltd, China. All chemicals used were of analytical grades and applied without further purification. Solutions were all made using doubly distilled water.

\section{Methods}

a) The acidimetric method as corrosion monitoring method

In this work the $\mathrm{pH}$ of the acid solution (corrodant) before insertion of coupons was determined using the $\mathrm{pH}$ meter. A $60 \mathrm{~mL}$ solution of $0.5 \mathrm{M}$ sulphuric acid was taken into $100 \mathrm{~mL}$ beaker and the $\mathrm{pH}$ determined. Coupons which were first prepared as reported [12-15] were inserted into the solution, first without urea, using a thread and allowed to stay unstirred for 7 hours at a temperature of $301 \mathrm{~K}$. After retrieval of the coupon the $\mathrm{pH}$ of the solution was again determined. The initial and final concentrations of the acid solution were calculated, and the difference was related to the quantity of mild steel consumed by the acid solution during the corrosion process, from where the corrosion rate and inhibition efficiency were evaluated. This procedure was repeated at $305 \mathrm{~K}, 309 \mathrm{~K}$ and $313 \mathrm{~K}$. Thereafter, the same quantity of the acid solution containing $100 \mathrm{ppm}$ of urea was used and the procedure repeated at these different temperatures. It was subsequently carried out at 200 ppm, 300 ppm, 400 ppm and 500 ppm urea concentrations. Each result reported is an average of triplicate readings.

\section{The hydrogen ion concentration}

The hydrogen ion, $\left(\mathrm{H}^{+}\right)$, was calculated in each case using the equation (1) below.

$$
\mathrm{pH}=-\log \left[\mathrm{H}^{+}\right]
$$




\section{Corrosion rate}

The corrosion rate (CR) of mild steel sample was calculated using equation (2) below

$$
C_{\mathrm{R}}\left(\mathrm{mol} \mathrm{dm}^{-3} \mathrm{~cm}^{-2} \mathrm{~h}^{-1}\right)=\frac{\left[\Delta \mathrm{H}^{+}\right]}{A t}
$$

where $\left[\Delta \mathrm{H}^{+}\right]$is the difference between the initial and final concentration of $\mathrm{H}^{+}, A$ the surface area of the coupon in $\mathrm{cm}^{2}$ and $t$, the time in hours.

\section{Inhibition efficiency}

The inhibition efficiency was evaluated using equation (3).

$$
\text { Inhibition efficiency } \% I E=1-\left(\frac{\left[\Delta \mathrm{H}^{+}\right]_{\text {inh }}}{\left[\Delta \Delta \mathrm{H}^{+}\right]_{\mathrm{uninh}}}\right) \times 100 \%
$$

where, $\left[\Delta \mathrm{H}^{+}\right]_{\text {inh }}$ and $\left[\Delta \mathrm{H}^{+}\right]_{\text {uninh }}$ are changes in $\mathrm{H}^{+}$concentration in the presence and absence of inhibitor, respectively.

Surface coverage

The surface coverage, $\theta$, was evaluated using equation (4) below:

$$
\theta=1-\left(\frac{\left[\Delta \mathrm{H}^{+}\right]_{\text {inh }}}{\left[\Delta \Delta \mathrm{H}^{+}\right]_{\text {uninh }}}\right)
$$

\section{b) Weight loss measurement}

A prepared coupon as reported above was weighed and then immersed in $60 \mathrm{~mL}$ of the acid solution in a $100 \mathrm{~mL}$ beaker applying the above conditions and procedure. Upon retrieval the coupon was washed several times in distilled water, degreased in ethanol and then immersed in acetone then kept in a desiccator to bring it to ambient temperature before determining the final weight and the difference in weight taken $[11,16]$. The same procedure was repeated upon introduction of various concentrations of the urea into the acid solution.

Corrosion rate

$$
\text { Corrosion rate }(\mathrm{CR})=\frac{W_{\mathrm{L}}}{A t},
$$

where $\mathrm{CR}$ is corrosion rate in $\mathrm{mg} \mathrm{cm}^{-2} \mathrm{~h}^{-1}, W_{\mathrm{L}}$ is weight loss in milligrams, $A$ the surface area of the coupon in $\mathrm{cm}^{2}$ and $t$ the time in hours [3,4]. 


\section{Inhibition efficiency and Surface Coverage}

The inhibition efficiency (\%IE) and surface coverage $(\theta)$ of each concentration of the inhibitor was evaluated using equations (6) and (7) respectively $[1-5,15]$.

$$
\begin{gathered}
I E=\frac{W_{0}-W_{1}}{W_{0}} \times 100 \% \text { or } I E=1-\frac{W_{1}}{W_{0}} \times 100 \% \\
\theta=1-\frac{W_{1}}{W_{0}}
\end{gathered}
$$

where $W_{1}$ and $W_{0}$ are weight losses in grams in the presence and absence of inhibitors respectively [11].

\section{Results and Discussion}

\section{Results}

The results of study are summarized in Tables $1-6$ as follows.

\begin{tabular}{|c|c|c|c|c|}
\hline \multicolumn{5}{|c|}{ Corrosion rate (mol dm $\left.{ }^{-3} \mathbf{c m}^{-2} \mathbf{h}^{-1}\right)$} \\
\hline Conc. (ppm) & $301 \mathrm{~K}$ & $305 \mathrm{~K}$ & $309 \mathrm{~K}$ & $313 \mathrm{~K}$ \\
\hline Blank & $1.38 \cdot 10^{-3}$ & $1.64 \cdot 10^{-3}$ & $1.94 \cdot 10^{-3}$ & $2.30 \cdot 10^{-3}$ \\
\hline 100 & $9.37 \cdot 10^{-4}$ & $1.18 \cdot 10^{-3}$ & $1.47 \cdot 10^{-3}$ & $1.86 \cdot 10^{-3}$ \\
\hline 200 & $8.19 \cdot 10^{-4}$ & $1.05 \cdot 10^{-3}$ & $1.33 \cdot 10^{-3}$ & $1.71 \cdot 10^{-3}$ \\
\hline 300 & $7.68 \cdot 10^{-4}$ & $9.30 \cdot 10^{-4}$ & $1.18 \cdot 10^{-3}$ & $1.57 \cdot 10^{-3}$ \\
\hline 400 & $6.50 \cdot 10^{-4}$ & $8.05 \cdot 10^{-4}$ & $1.10 \cdot 10^{-3}$ & $1.43 \cdot 10^{-3}$ \\
\hline 500 & $5.31 \cdot 10^{-4}$ & $7.34 \cdot 10^{-4}$ & $9.62 \cdot 10^{-4}$ & $1.35 \cdot 10^{-3}$ \\
\hline
\end{tabular}

Table 1. Values of corrosion rate (CR) for acidimetric method.

Table 2. Values of corrosion rate (CR) for weight loss method.

\begin{tabular}{ccccc}
\hline \multicolumn{5}{c}{ Corrosion rate $\left(\mathbf{m g ~ c m}^{-\mathbf{2}} \mathbf{~}^{\mathbf{- 1}}\right)$} \\
\hline Conc. $(\mathbf{p p m})$ & $\mathbf{3 0 1} \mathbf{~ K}$ & $\mathbf{3 0 5} \mathbf{~ K}$ & $\mathbf{3 0 9} \mathbf{~ K}$ & $\mathbf{3 1 3 ~ K}$ \\
\hline Blank & 1.5650 & 1.7645 & 1.9305 & 2.4870 \\
100 & 1.0922 & 1.3196 & 1.5122 & 2.0434 \\
200 & 0.9786 & 1.2207 & 1.3905 & 1.8710 \\
300 & 0.8607 & 1.0432 & 1.2574 & 1.7214 \\
400 & 0.7365 & 0.9393 & 1.1674 & 1.6377 \\
500 & 0.6642 & 0.8544 & 1.0179 & 1.5363 \\
\hline
\end{tabular}


Table 3. Inhibition efficiency (\%IE) of urea as corrosion inhibitor of mild steel corrosion at different temperatures for both methods.

\begin{tabular}{ccccc}
\hline \multicolumn{5}{c}{ \% IE } \\
\hline \multirow{2}{*}{ Conc. $(\mathbf{p p m})$} & $\mathbf{3 0 1} \mathbf{K}$ & $\mathbf{3 0 5} \mathbf{K}$ & $\mathbf{3 0 9} \mathbf{K}$ & $\mathbf{3 1 3 ~ K}$ \\
\hline \multirow{2}{*}{100} & 32.23 & 27.79 & 24.46 & 19.16 \\
& $(30.20)$ & $(25.22)$ & $(21.67)$ & $(17.84)$ \\
\hline \multirow{2}{*}{200} & 40.79 & 35.55 & 31.77 & 25.35 \\
& $(37.49)$ & $(30.82)$ & $(27.67)$ & $(24.77)$ \\
\hline \multirow{2}{*}{300} & 44.48 & 43.14 & 39.07 & 31.42 \\
& $(45.02)$ & $(40.88)$ & $(34.87)$ & $(30.78)$ \\
\hline \multirow{2}{*}{400} & 52.98 & 50.81 & 47.55 & 37.55 \\
& $(52.96)$ & $(46.77)$ & $(39.53)$ & $(34.15)$ \\
\hline \multirow{2}{*}{500} & 61.59 & 55.15 & 50.49 & 41.25 \\
& $(57.57)$ & $(51.58)$ & $(47.28)$ & $(38.23)$ \\
\hline
\end{tabular}

*Values in parentheses are for weight loss method.

Table 4. Values of kinetic and thermodynamic parameters of mild steel corrosion inhibition using urea as inhibitor.

\section{$\Delta G_{\text {ads }}\left(\mathrm{kJ} \mathrm{mol}^{-1}\right)$}

\begin{tabular}{|c|c|c|c|c|c|c|c|c|}
\hline $\begin{array}{l}\text { Conc. } \\
\text { (ppm) }\end{array}$ & $\begin{array}{c}E_{\mathrm{a}} \\
\left(\mathrm{kJ} \mathrm{mol}^{-1}\right)\end{array}$ & $\underset{\left(\mathrm{kJ} \mathrm{mol}^{-1}\right)}{\Delta H_{\mathrm{ads}}}$ & $\begin{array}{c}\Delta S_{\mathrm{ads}} \\
\left(\mathrm{J} \mathrm{mol}^{-1}\right)\end{array}$ & $\underset{\left(\mathrm{kJ} \mathrm{mol}^{-1}\right)}{Q_{\mathrm{ads}}}$ & $301 \mathrm{~K}$ & $305 \mathrm{~K}$ & $309 \mathrm{~K}$ & $313 \mathrm{~K}$ \\
\hline Blank & $\begin{array}{c}33.43 \\
(28.99)\end{array}$ & $\begin{array}{c}30.65 \\
(26.43)\end{array}$ & $\begin{array}{c}-239.5 \\
(-195.8)\end{array}$ & - & - & - & - & - \\
\hline 100 & $\begin{array}{c}44.76 \\
(39.54)\end{array}$ & $\begin{array}{c}42.24 \\
(36.85)\end{array}$ & $\begin{array}{c}-204.2 \\
(-163.2)\end{array}$ & $\begin{array}{c}-44.38 \\
(-44.53)\end{array}$ & $\begin{array}{c}-13.95 \\
(-13.72)\end{array}$ & $\begin{array}{c}-13.60 \\
(-13.27)\end{array}$ & $\begin{array}{c}-13.34 \\
(-12.93)\end{array}$ & $\begin{array}{c}-12.70 \\
(-12.47)\end{array}$ \\
\hline 200 & $\begin{array}{c}48.02 \\
(40.72) \\
\end{array}$ & $\begin{array}{c}44.99 \\
(38.16) \\
\end{array}$ & $\begin{array}{c}-196.2 \\
(-160.0)\end{array}$ & $\begin{array}{c}-44.97 \\
(-38.15)\end{array}$ & $\begin{array}{c}-13.15 \\
(-12.80)\end{array}$ & $\begin{array}{c}-12.76 \\
(-12.22)\end{array}$ & $\begin{array}{c}-12.49 \\
(-12.02)\end{array}$ & $\begin{array}{c}-11.83 \\
(-11.75)\end{array}$ \\
\hline 300 & $\begin{array}{c}47.18 \\
(44.45)\end{array}$ & $\begin{array}{c}44.34 \\
(41.89)\end{array}$ & $\begin{array}{c}-199.1 \\
(-148.9)\end{array}$ & $\begin{array}{c}-36.16 \\
(-41.00)\end{array}$ & $\begin{array}{c}-12.51 \\
(-12.56)\end{array}$ & $\begin{array}{c}-12.54 \\
(-12.30)\end{array}$ & $\begin{array}{c}-12.27 \\
(-11.81)\end{array}$ & $\begin{array}{c}-11.55 \\
(-11.48)\end{array}$ \\
\hline 400 & $\begin{array}{c}52.62 \\
(51.32)\end{array}$ & $\begin{array}{c}49.88 \\
(48.76)\end{array}$ & $\begin{array}{c}-182.1 \\
(-127.3)\end{array}$ & $\begin{array}{c}-39.37 \\
(-51.51)\end{array}$ & $\begin{array}{c}-13.36 \\
(-12.64)\end{array}$ & $\begin{array}{c}-12.59 \\
(-12.18)\end{array}$ & $\begin{array}{c}-12.42 \\
(-11.58)\end{array}$ & $\begin{array}{c}-11.51 \\
(-11.13)\end{array}$ \\
\hline 500 & $\begin{array}{c}60.32 \\
(52.78)\end{array}$ & $\begin{array}{c}58.15 \\
(50.21)\end{array}$ & $\begin{array}{c}-156.1 \\
(-123.4)\end{array}$ & $\begin{array}{c}-52.29 \\
(-49.57)\end{array}$ & $\begin{array}{c}-12.97 \\
(-12.55)\end{array}$ & $\begin{array}{l}-12.30 \\
(-12.10)\end{array}$ & $\begin{array}{c}-12.15 \\
(-11.82)\end{array}$ & $\begin{array}{c}-11.34 \\
(-11.01)\end{array}$ \\
\hline
\end{tabular}

*Values in parenthesis are for weight loss method. 
Table 5. Values of parameters of various adsorption isotherm studies for adsorption of urea unto to metal surface for acidimetric method.

\begin{tabular}{|c|c|c|c|c|c|c|c|}
\hline Isotherm & Temp. & $R^{2}$ & S.E & Slope & $\boldsymbol{K}_{\mathrm{ads}}$ & Isotherm constant & $\Delta G_{\mathrm{ads}}$ \\
\hline \multirow[t]{5}{*}{$\begin{array}{c}\text { Adejo- } \\
\text { Ekwenchi }\end{array}$} & & & & & & $B$ & \\
\hline & 301 & 0.8670 & 0.0402 & 0.3215 & 2.9302 & 0.3215 & -12.74 \\
\hline & 305 & 0.9458 & 0.0230 & 0.2963 & 2.6291 & 0.2963 & -12.64 \\
\hline & 309 & 0.9431 & 0.0205 & 0.2695 & 2.3725 & 0.3752 & -12.54 \\
\hline & 313 & 0.9522 & 0.0140 & 0.1986 & 1.9046 & 0.1986 & -12.13 \\
\hline \multirow[t]{5}{*}{ Freundlich } & & & & & & $n_{\mathrm{E}}$ & \\
\hline & 301 & 0.9623 & 0.0236 & 0.3828 & 0.7581 & 2.6123 & -9.36 \\
\hline & 305 & 0.9922 & 0.0123 & 0.4348 & 0.7403 & 2.2999 & -9.42 \\
\hline & 309 & 0.9883 & 0.0140 & 0.4674 & 0.7006 & 2.1395 & -9.40 \\
\hline & 313 & 0.9935 & 0.0141 & 0.4854 & 0.5732 & 2.0602 & -9.00 \\
\hline \multirow[t]{5}{*}{ Temkin } & & & & & & $A$ & \\
\hline & 301 & 0.9182 & 0.0375 & 0.3920 & 0.5699 & -2.9375 & -8.64 \\
\hline & 305 & 0.9697 & 0.0218 & 0.3965 & 0.5043 & -2.9042 & -8.45 \\
\hline & 309 & 0.9637 & 0.0233 & 0.3848 & 0.4632 & -2.9925 & -8.34 \\
\hline & 313 & 0.9682 & 0.0187 & 0.3190 & 0.4410 & -3.6097 & -8.32 \\
\hline \multicolumn{8}{|l|}{ Langmuir } \\
\hline & 301 & 0.9451 & 0.0555 & 1.2677 & 4.3840 & & -13.75 \\
\hline & 305 & 0.9772 & 0.0362 & 1.3182 & 3.7467 & & -13.53 \\
\hline & 309 & 0.9701 & 0.0446 & 1.3747 & 3.1736 & & -13.29 \\
\hline & 313 & 0.9711 & 0.0526 & 1.6566 & 2.4295 & & -12.76 \\
\hline \multirow[t]{5}{*}{ El-Awady } & & & & & & $Y$ & \\
\hline & 301 & 0.9252 & 0.0638 & 0.7043 & 2.2213 & 0.7043 & -12.05 \\
\hline & 305 & 0.9791 & 0.0339 & 0.7312 & 1.9467 & 0.7312 & -11.87 \\
\hline & 309 & 0.9769 & 0.0363 & 0.7364 & 1.6611 & 0.7364 & -11.62 \\
\hline & 313 & 0.9860 & 0.0258 & 0.6840 & 1.0914 & 0.6840 & -10.68 \\
\hline
\end{tabular}


Table 6. Values of parameters of various adsorption isotherm studies for adsorption of urea unto to metal surface weight loss method.

\begin{tabular}{|c|c|c|c|c|c|c|c|}
\hline Isotherm & Temp. & $R^{2}$ & S.E & Slope & $\boldsymbol{K}_{\mathrm{ads}}$ & Isotherm constant & $\Delta G_{\mathrm{ads}}$ \\
\hline \multirow[t]{5}{*}{$\begin{array}{c}\text { Adejo- } \\
\text { Ekwenchi }\end{array}$} & & & & & & $B$ & \\
\hline & 301 & 0.9348 & 0.0265 & 0.3084 & 2.7804 & 0.3084 & -12.61 \\
\hline & 305 & 0.9344 & 0.0224 & 0.2734 & 2.4010 & 0.2734 & -12.41 \\
\hline & 309 & 0.9123 & 0.0231 & 0.2308 & 2.0946 & 0.2308 & -12.22 \\
\hline & 313 & 0.9807 & 0.1745 & 0.2537 & 1.4942 & 0.2537 & -11.50 \\
\hline \multirow[t]{5}{*}{ Freundlich } & & & & & & $n_{\mathrm{E}}$ & \\
\hline & 301 & 0.9871 & 0.0132 & 0.4089 & 0.7535 & 2.4456 & -9.34 \\
\hline & 305 & 0.9756 & 0.0246 & 0.4621 & 0.7029 & 2.1640 & -9.29 \\
\hline & 309 & 0.9840 & 0.0196 & 0.4741 & 0.6256 & 2.1093 & -9.11 \\
\hline & 313 & 0.9983 & 0.0965 & 0.4738 & 0.5330 & 2.1106 & -8.81 \\
\hline \multirow[t]{5}{*}{ Temkin } & & & & & & $A$ & \\
\hline & 301 & 0.9619 & 0.0248 & 0.3958 & 1.0603 & -0.5885 & -10.20 \\
\hline & 305 & 0.9531 & 0.0275 & 0.3870 & 1.2492 & -0.5355 & -10.75 \\
\hline & 309 & 0.9429 & 0.0271 & 0.3499 & 1.4884 & -0.4751 & -11.34 \\
\hline & 313 & 0.9899 & 0.0874 & 0.2890 & 1.8335 & -0.3998 & -12.03 \\
\hline \multicolumn{8}{|l|}{ Langmuir } \\
\hline & 301 & 0.9743 & 0.0376 & 1.2966 & 4.1322 & & -13.60 \\
\hline & 305 & 0.9603 & 0.0495 & 1.3521 & 3.1726 & & -13.11 \\
\hline & 309 & 0.9457 & 0.0653 & 1.4888 & 2.6695 & & -12.79 \\
\hline & 313 & 0.9908 & 0.0310 & 1.8587 & 2.4582 & & -12.79 \\
\hline \multirow[t]{5}{*}{ El-Awady } & & & & & & $Y$ & \\
\hline & 301 & 0.9699 & 0.0404 & 0.7172 & 2.0956 & 0.7172 & -11.90 \\
\hline & 305 & 0.9649 & 0.0448 & 0.7354 & 1.6873 & 0.7354 & -11.51 \\
\hline & 309 & 0.9643 & 0.0428 & 0.6991 & 1.3026 & 0.6991 & -11.00 \\
\hline & 313 & 0.9980 & 0.1616 & 0.6482 & 1.0462 & 0.6482 & -10.57 \\
\hline
\end{tabular}




\section{Discussion}

In this acidimetric method, the corrosion reaction of the metal was monitored as a function of change of the concentration of hydrogen ion $\left(\mathrm{H}^{+}\right)$in the acid solution. The equation for the corrosion of iron metal in dilute sulphuric acid solution can be represented thus;

$$
\mathrm{Fe}+\mathrm{H}_{2} \mathrm{SO}_{4} \rightarrow \mathrm{FeSO}_{4}+\mathrm{H}_{2} \mathrm{O}
$$

It may, therefore, be argued that iron (ii) sulphate produced, being a salt formed from a strong acid and weak base, will undergo hydrolysis as depicted by equation (9). The $\mathrm{H}^{+}$ can have effect on the measured value of $\mathrm{pH}$, thereby raising the question of reliability of this method.

$$
\mathrm{Fe}^{2+}+\mathrm{HOH}=[\mathrm{FeOH}]^{+}+\mathrm{H}^{+}
$$

It must be, however, considered that factors which affect the acidity of a salt solution are mainly size, charge density of the cation and nature of the solution. Ion of small size and high charge easily hydrolyses to yield considerable amount $\mathrm{H}^{+}$in aqueous solution to affect acidity, with $\mathrm{Fe}^{3+}$ and $\mathrm{Al}^{3+}$ being good examples $[11,12]$. Iron(II) ion is not too small and the charge is not too high either, so the extend of hydration will not be significant to alter the $\mathrm{H}^{+}$level to make the results unreliable. Also, in acidic solution, like the medium this experiment was conducted, the equilibrium in equation (9) shifts more to the left-hand side and therefore the concentration of $\mathrm{H}^{+}$will be significantly low. This is why aqueous solution of $\mathrm{FeSO}_{4}$ in acidic medium is always clear.

The corrosion rate as observed (Table 1) decreased with increase in concentration of urea, but increased with rise in temperature. This is a clear propensity of inhibitive action of the urea for the corrosion of the mild steel sample in the acid medium [17]. The same trend was observed in the case of weight loss method (Table 2). The two techniques gave very comparable results of inhibition efficiency (\%IE) (Table 3). This goes to suggest that acidimetric technique can be conveniently adopted for corrosion inhibition monitoring/ evaluation. However, values obtained through acidimetric technique are slightly higher than those of the weight loss technique. As earlier pointed, the possibilities of introduction of errors into results are greater in the weight loss technique than the acidimetric method.

The \%IE was observed, generally, to increase with increase in the inhibitor concentration, but decreased with temperature rise, all for both techniques. This trend \%IE with increase in temperature is a pointer that urea molecules were physically adsorbed onto the mild steel surface $[2,13]$.

As shown in Table 3, the values of activation energy $\left(E_{\mathrm{a}}\right)$ and thermodynamic parameters for the two methods are quite comparable. The $E_{\mathrm{a}}$ and enthalpy of activation $\left(\Delta H_{\text {ads }}\right)$ values for the corrosion process were found out to rise with the introduction of urea into the acid solution, and progressively increased with increase in the concentration. However, $E_{\mathrm{a}}$ values are below the $80 \mathrm{~kJ} / \mathrm{mol}$, the threshold for physisorption $[14,18]$. Enthalpy of activation measures the height of the energy barrier, particularly the strengths 
within and between reactants that must be overcome to attain the transition state. The average difference in $E_{\mathrm{a}}-\Delta H_{\mathrm{ads}}$ value for both methods is approximately equal to $2.55 \mathrm{~kJ} / \mathrm{mol}$, the value of $R T$ ( $R$ is the universal gas constant and $T$ the average of the temperatures used for the study). This goes to show that the corrosion process is a unimolecular reaction [19].

The negative values of entropy of adsorption as shown in table 3 for the two methods imply that the activated complex in the rate-determining step followed associative mechanism, meaning a decrease in disorderliness as the reactant molecules proceeded to the activated complex $[8,9]$. Heat of adsorption values are all negative, an indication that the corrosion process is exothermal [16]. The values of $\Delta G_{\text {ads }}$ (Table 3) are comparably same for the two methods and all below $-20 \mathrm{~kJ} / \mathrm{mol}$, supportive of physisorption proposed above.

The mechanism of inhibitive action of organic molecules has been attributed to their adsorption unto the surface of the metal and adsorption isotherm models have extensively used in its confirmation [13]. Many researchers have employed the use of the coefficient of determination, $R^{2}$, to determine the fitness of adsorption data unto adsorption isotherm models and $\Delta G_{\text {ads }}$ to ascertain whether the adsorption process is physisorption or chemisorption. However, many others have pointed out the inadequacy of these two parameters in the characterisation of adsorption process [20,21]. The Adejo-Ekwenchi isotherm has been effectively employed to resolve this ambiguity, as the parameter $b$ of the isotherm model can clearly distinguish between physisorption and chemisorption [8].

Tables 4 and 5 are the isotherm fittings based on $R^{2}$ and going by it the adsorption process seemly follows the Adejo-Ekwenchi, Freundlich, Langmuir, Temkin and ElAwady adsorption isotherm models for the two methods. Values of $K_{\text {ads }}$ for both methods are positive for all the isotherms, a clear indication of favourable adsorption. For the Adejo-Ekwenchi isotherm, the value $b$ parameter value decreases with increase in temperature in both cases, clearly showing that the adsorption mechanism is physisorption $[22,23]$. With the combination of $\Delta G_{\text {ads }}$ values and parameter $b$ of the Adejo-Ekwenchi isotherm the isotherm best fit for this adsorption are the Langmuir and El-Awady isotherm models.

\section{Conclusion}

From the above results, the efficacy of acidimetric method has been demonstrated, as the results obtained through it are quite comparable with that of weight loss method. In fact, the acidimetric method produced better results than the weight loss method. The method can, therefore, be adopted as fast and convenient corrosion evaluation method. In addition, this work has demonstrated that the adsorption of urea unto to the surface of mild steel is physisorption and can best be modelled by Langmuir and El-Awady isotherms. 


\section{Acknowledgements}

The Authors wish to express their profound gratitude to Tertiary Education Fund (tetFUND) Nigeria for providing a grant to support the research work. We also wish to thank, immensely, the technical staff of Department of Chemistry, Benue State University, Makurdi-Nigeria for the assistance provided and the Department itself for providing the laboratory facilities and space for this work.

\section{References}

1. L. Yang, Techniques for Corrosion Monitoring, $1^{\text {st }}$ ed., 2008, Woodhead Publishing, USA.

2. S.O. Adejo, M.M. Ekwenchi, F. Momoh and E. Odiniya, Int. J. Modern Chem., 2012, 1, no. $3,125$.

3. S.O. Adejo, S.G. Yiase, U.J. Ahile, T.G. Tyohemba and J.A. Gbertyo, Archives Appl. Sci. Research, 2013, 5, no. 1, 25.

4. NACE International: The Corrosion Society, Techniques for Monitoring Corrosion and Related Parameters in Field Applications, NACE International Publication 3T 199, 1999.

5. A.S. Abdullah, IRACST - Eng. Sci. Tech: An Int. J., 2015, 5, no. 6, 2250.

6. R.T. Loto, C.A. Loto and A.P.I. Popoola, J. Mat.Environ. Sci., 2012, 3, no. 5, 885-894.

7. B.E. Amitha-Rani and B.B.J. Basu, Int. J. Corr., 2012, doi: 10.1155/2012/380217

8. S.K. Sharma, A. Peter and I.B. Obot, J. Anal. Sci. Tech, 2015, 6:26. doi: 10.1186/s40543-015-0067-0

9. P. Udhayakala, T.V. Rajendirin and S. Gunasekaran, J. Adv. Sci. Res., 2012, 3, no. 2, $71-77$.

10. E. McCafferty, Introduction to Corrosion Science, Alexandria: Springer Science + Business Media, 2010.

11. W. Villamizar-Suarez, J.M. Malo, A. Matinez-Villafane and J.G. Chacon-Nava, J. Appl. Electrochem., 2011, 41, 1269.

12. K. Orubite-Okorosaye and N.C. Oforka, J. Appl. Sci. Environ. Manage., 2004, 8, no. 1, 57.

13. S.O. Adejo and M.M. Ekwenchi, IOSR J. Appl. Chem., 2014, 6, no. 5, 66. doi: 10.9790/5736-0656671

14. S.O. Adejo, J.A. Gbertyo and J.U. Ahile, Intern. J. Modern Chem., 2013, 4, no. 3, 137.

15. A. Peter and S.K. Sharma, Int. J. Corros. Scale Inhib., 2017, 6, no. 2, 112-131. doi: 10.17675/2305-6894-2017-6-2-2

16. A.K. Maayta, Asian J. Chem., 2006, 18, no. 1, 566. www.researchgate.net

17. M.S. Silberberg, Chemistry: The Molecular nature of matter and change, $2^{\text {nd }}$ ed., McGraw-Hill Higher Education, 2000, pp. 785-788. 
18. R. Chang, Chemistry, $3^{\text {rd }}$ ed., McGraw-Hill Publishing Company, New York, 1988, p. 664.

19. R.N. Nair, S. Sharma, I.K. Sharma, P.S. Verma and A. Sharma, Rasayan J. Chem, 2010,3 , no. 4,783 .

20. A.A. Siaka, N.O. Eddy, S.O. Idris, A. Muhammad, C.M. Elinge and F.A. Atiku, Innovations Sci. Eng., 2012, $2,41$.

21. M. Lebrini, F. Robert and C. Ross, Int. J. Electrochem. Sci., 2010, 5, 1698.

22. Y.S. Ho, J.F. Porter and G. McKay, Water, Air Soil Poll., 2000, 141, 1.

23. A. Popova, M. Christov, A. Vasilev and A. Zwetanova, Corros. Sci., 2011, 53, 679.

24. S.O. Adejo, M.M. Ekwenchi, J.A. Gbertyo, T. Menenge and J.O. Ogbodo, J. Adv. Chem., 2014, 10, no. 5, 2737.

25. S.O. Adejo, M.M. Ekwenchi, J.U. Ahile, J.A. Gbertyo and A. Kaior, J. Emerging Trends Eng. Appl. Sci. (JETEAS), 2014, 5, no. 8, 201. 